\title{
SENTINEL-2 ANALYSIS OF FLOODED AREAS: APPLIED CASE STUDY - LA SAFOR WETLAND, SPAIN
}

\author{
JESÚS PENA-REGUEIRO ${ }^{1}$, MARIA-TERESA SEBASTIÁ-FRASQUET ${ }^{1}$, \\ JESÚS A. AGUILAR-MALDONADO ${ }^{1}$, JAVIER ESTORNELL ${ }^{2}$, \\ JOSÉ-ANDRÉS SANCHIS-BLAY ${ }^{1}$, SERGIO MORELL-MONZÓ ${ }^{1} \&$ VICENT ALTUR-GRAU $^{1}$ \\ ${ }^{1}$ Instituto de Investigación para la Gestión Integrada de Zonas Costeras, Universitat Politècnica de València, Spain \\ ${ }^{2}$ Grupo de Cartografía GeoAmbiental y Teledetección, Universitat Politècnica de València, Spain
}

\begin{abstract}
La Safor wetland is a representative coastal wetland in the Valencia Region (eastern Spain, Mediterranean Sea). This wetland is recognized at an international level as a Special Protection Area (SPAs) for birds and a Site of Community Importance (SCIs) (Habitats Directive, European Council Directive). The wetland is located on a detrital plain aquifer which in turn is fed by a karstic aquifer in the near limestone reliefs. The flooded surface is variable and depends on pluviometry among other factors. The objective of this study is to analyse the effects of the flooded surface on land uses by remote sensing and Airborne LiDAR data. Sentinel-2A images processed at level 1C were obtained from Copernicus. LiDAR data was used to detect the most vulnerable areas affected by floods. In the results, we analysed the impact of the maximum flooded surface on land uses. We propose several corrective actions on the drainage net based on our analysis. This methodology can be applied to other wetland areas of similar characteristics. The advantage is the high spatial resolution which makes the methodology suitable for small sized wetlands.
\end{abstract}

Keywords: flooding, wetland, restoration, LiDAR, remote sensing.

\section{INTRODUCTION}

Coastal wetlands are important ecosystems that are endangered because of intensive human pressure in these areas [1]. Wetlands provide a wide range of ecosystem services, particularly they are important providers of all water-related ecosystem services, among them their capacity to maintain and improve water quality, flood control, groundwater replenishment, shoreline stabilisation and storm protection and climate change mitigation and adaptation [2]-[4]. Wetlands play an important role in maintaining local water quality. They can act as filtering systems, removing sediment, nutrients (mainly nitrogen and phosphorus) and pollutants (such as pesticides from agricultural runoff) from water. Their holding capacity helps control floods and prevents water logging of crops and adjacent urban areas [3], [5]. Preserving and restoring them can often provide the level of flood control more affordable than dredge operations and levees [5]. In fact, there are studies that calculate the benefits of economical activities in wetlands such as intensive agriculture and shrimp farms, and they are between $60 \%$ and $75 \%$ lower - in the long term - than the benefits from wetland conservation and sustainable use [2], [6]. Nowadays, projects to restore their functions are being designed and implemented.

Remotely sensed data can provide spatial maps of water bodies, with different accuracy depending on the sensor, that can be used to increase the knowledge of these areas [7]-[10]. The analysis of remote data can be based on supervised classification and the definition of water indices and their subsequent classification using thresholds [9], [10]. From 2015 onward, Sentinel-2A/B images are available (ESA), with high temporal resolution and bands of $10 \mathrm{~m}$ that allow to extract small-sized water bodies [7]. LIDAR (Light Detection and Ranging or Laser Imaging Detection and Ranging) data can be used to obtain synoptic digital elevation models (DEMs). The information on wetland elevation obtained from LIDAR data 
is very accurate and can be used for different purposes such as habitat mapping and flood inundation mapping [11]. The accuracy of the LIDAR-derived DEM can range from 0.03 to $0.25 \mathrm{~m}$ depending on the vegetation cover classes [11].

The objective of this study is to analyse the effects of the flooded surface on land uses by remote sensing and Airborne LiDAR data on a Mediterranean coastal wetland "La Safor wetland". Currently, the municipalities of this wetland are competing for European funds for projects to recover hydraulic infrastructures in protected areas. So, a complete diagnosis of the areas most vulnerable to flooding is necessary.

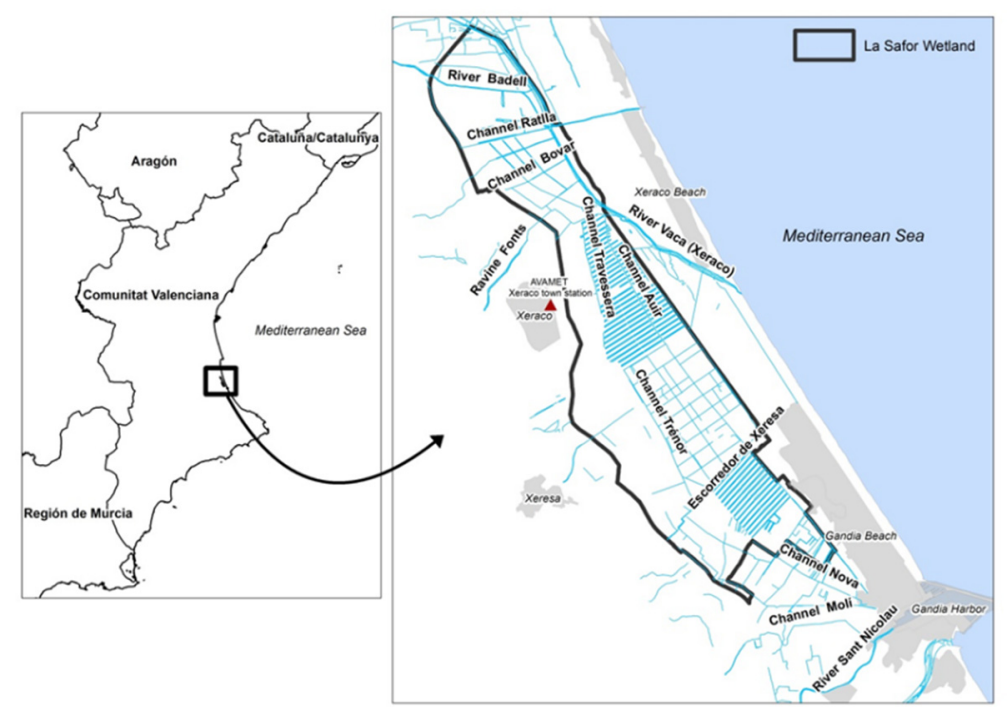

Figure 1: Study area location. The red triangle is the Xeraco town meteorological station.

\section{MATERIALS AND METHODS}

\subsection{Study area}

La Safor wetland is in south Valencia, Spain and extends to four municipalities (Gandia, Xeresa, Xeraco and Tavernes de la Valldigna) (Figs 1 and 2). It is included in both the Valencian Wetlands Inventory, and in the Spanish Wetlands, and at international level, is a Special Protection Areas (SPAs) for birds and Site of Community Importance (SCI). This coastal wetland is above a detrital aquifer, and its main freshwater input comes from groundwater discharge of the adjacent karstic aquifers and is separated from the sea by a sand bar [1]. The flooded surface is variable and depends on pluviometry among other factors [7]. La Safor wetland has suffered intense agricultural transformations mainly from the seventies onward [1]. Nowadays, the main land uses are citrus and horticultural crops according to the Corine Land Cover obtained from the Valencian Cartography Institute (Fig. 2).

Two watercourses are the main drainage of the wetland, San Nicolás and Vaca Rivers, to the north and south respectively (Fig. 1). Both rivers drain the wetland and flows into the Mediterranean Sea. San Nicolás flows into the Gandia Harbour and Vaca River flows directly into the sea in Xeraco. There is a built grid of channels that served for irrigation purposes before it has been substituted by drip irrigation. These channels also contributed to wetland 
drainage as they were connected either to the above described rivers or directly to the sea. However, two main factors caused the deterioration and even partial disappearance of these channels. The change in the irrigation system caused an important reduction in maintenance tasks by farmers. The urban pressure, especially in Gandia municipality, caused for example the disappearance of Escorredor de Xeresa in its final course to the sea (Fig. 3). In 1956, this channel outflow in behind the dunes to a channel parallel to the sea. Partially due to this abandonment of hydraulic infrastructures there exists flooding problems in the agricultural and urban areas.

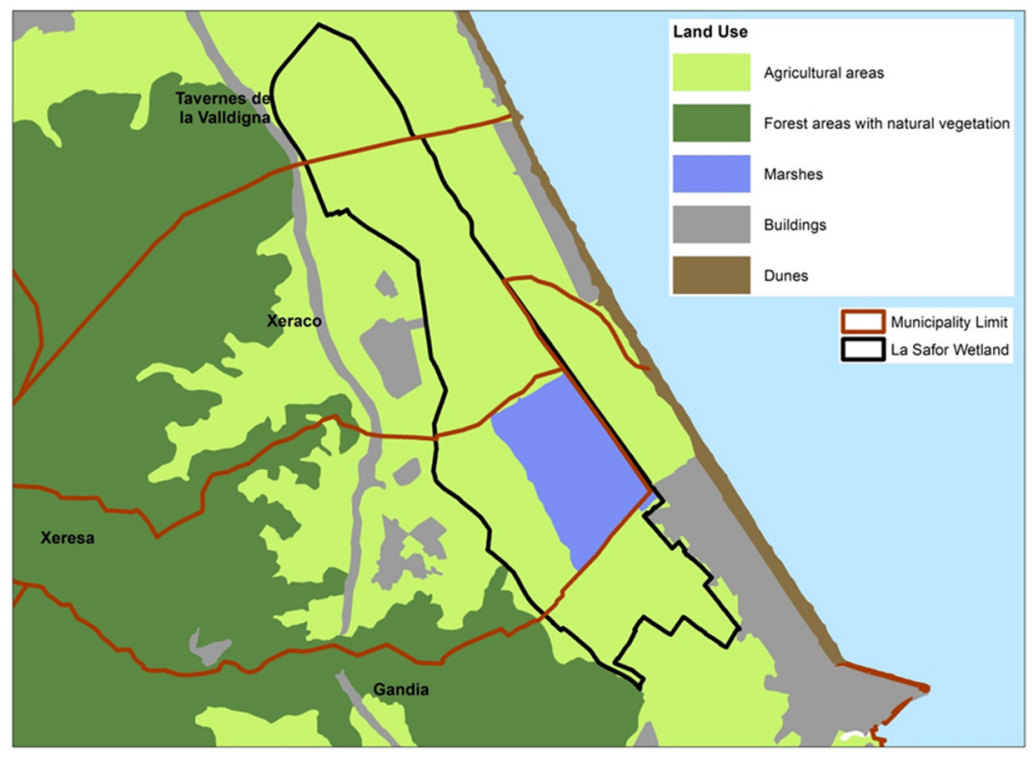

Figure 2: Land uses and municipality limits in the La Safor wetland.

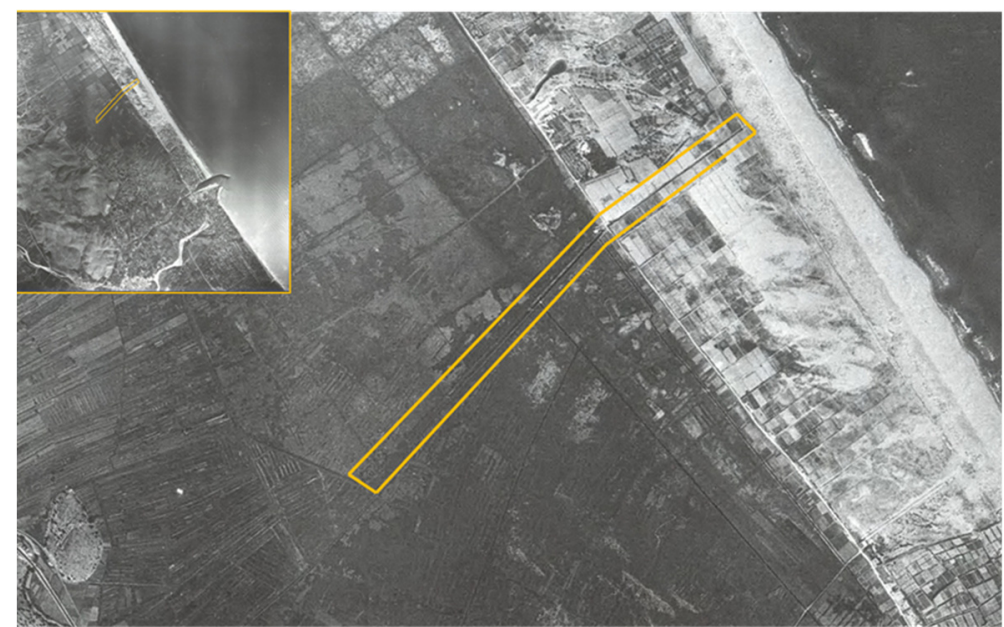

Figure 3: Aerial image, 1956. Marked in yellow is the channel "Escorredor de Xeresa". 


\subsection{Image processing}

The official cartography of protected areas (Valencian Wetland Inventory) was used to delimitate wetland (Figs 1 and 2). The LIDAR-derived DEM was calculated for $2 \mathrm{~m}$ pixel, the orthometric heights information was obtained from LiDAR sensor with a density of 0.5 points $/ \mathrm{m}^{2}$ (PNOA 2007 CC BY 4.0 www.scne.es).Sentinel-2A images from the Multispectral Instrument (MSI) processed at level 1C were obtained from Copernicus (https://scihub.copernicus.eu/dhus/\#/home). The atmospheric correction was done with Sen2Cor tool (version 02.05.05) using SNAP software (ESA, version 6.0.0). The NDWI index was calculated according to Pena-Regueiro et al. [7] see eqn (1):

$$
N D W I=\frac{B 03-B 08}{B 03+B 08} \text {. }
$$

B03 and B08 are Sentinel-2 bands with $10 \mathrm{~m}$ spatial resolution. For each date, we delimited the water polygons using the -0.30 , threshold defined by Pena-Regueiro et al. [7]. The acquisition date of the Sentinel 2A image was chosen to show the higher extent of the flooded area. This depends on the precipitation regime, so pluviometry data was obtained from the closest meteorological station, Xeraco town station (Fig. 1) [12].

\section{RESULTS AND DISCUSSION}

The LIDAR-derived DEM can be observed in Fig. 4. La Safor wetland is in a depressed area between karstic relieves and the Mediterranean Sea. Most of the protected area is below 2.5 m.a.s.l. In the north part, there is an agricultural area dedicated to horticultural crops that is below sea level (between -1.5-0 m.a.s.1.), represented by the white area in Fig. 4(b).

From the 1970s onward, a new production system called "bancs" was developed in La Safor wetland [1] that raised the height of agricultural plots with the materials dredged from adjoining plots which became ponds. Also, mining licenses for peat were granted when excavating up to one and a half meters below ground level. In the 1980s and 1990s, the agricultural transformation projects continued to create large citrus farms [1]. This transformation can be appreciated in Fig. 4, plots between 1.5-2.5 m adjoining plots between 0.5-1 m (dark blue-pink areas), and plots between 3-5 m adjoining plots between 1.5-2.5 m (green-dark blue areas). The most depressed plots correspond to the excavated ponds, and the highest to the "bancs".

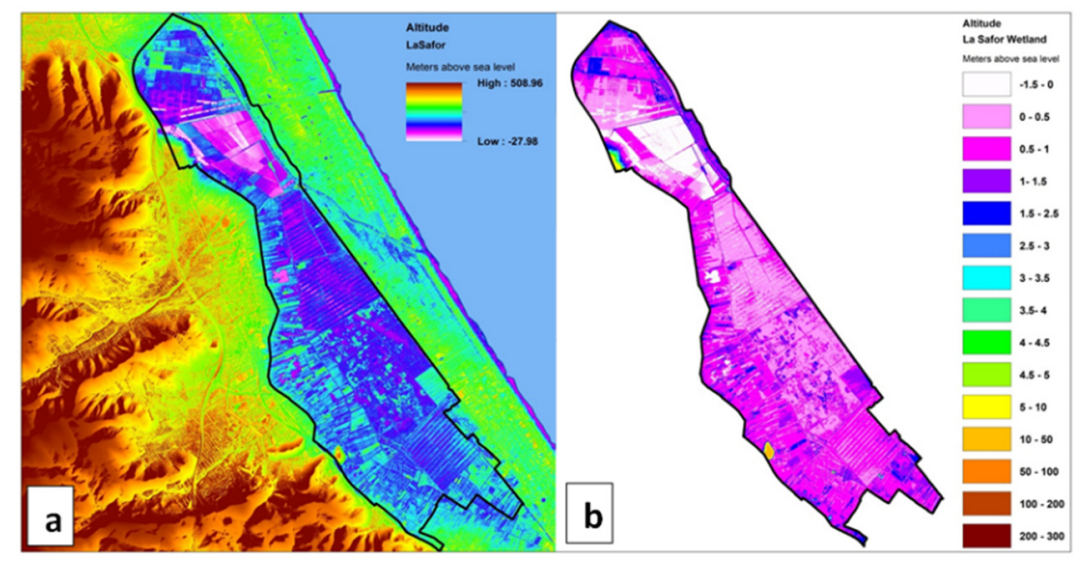

Figure 4: LIDAR-derived digital elevation model. 
In Fig. 5, we can observe the results of mapping water bodies by the NDWI methodology [7]. The Sentinel-2A image was captured on January 16, 2017. The results show a total flooded surface of $1.46 \mathrm{~km}^{2}$. The image data was selected for two reasons. The average annual precipitation for the Xeraco town meteorological station is $709.2 \mathrm{~mm}$, and the two months before the image data there was an accumulated precipitation of $326.7 \mathrm{~mm}$. Then, the image was captured after a wet period with maximum precipitation in 24 hours of $50.6 \mathrm{~mm}$ on November 28, 2016, $71.8 \mathrm{~mm}$ on December 5, 2016 and two consecutive days with $46.1 \mathrm{~mm}$ on December 18 and 19, 2016. Usually, dense vegetation prevents remote sensing indices to detect water, and we can only observe free vegetation water bodies. But, on November 9, 2016, there was a fire in the wetland that burned $90 \mathrm{Ha}$ (Fig. 6). The disappearance of dense marsh vegetation made possible to appreciate the water layer after the rainy period. The main water polygon $\left(1 \mathrm{~km}^{2}\right.$ flooded area) is in an area called "Les Galerasses" which is where marsh is better conserved (Fig. 2). We can also appreciate, north and south of this bigger water polygon, longitudinal polygons that correspond to the above described ponds. In the most depressed area, white polygon in Fig. 4, we do not appreciate relevant flooding. This can be explained because in these plots there is a big farm of horticultural crops, and they have four water pumps to discharge water to the Vaca river.

Local authorities (Gandia, Xeresa, Xeraco and Tavernes councils) usually need to deal with conflicting interests among different users, i.e. owners, farmers, irrigators, hunters, fishermen, residents, conservationists, and companies. Farmers are grouped in irrigation communities, such as Gandia's Irrigation Community. For these users, it is very important to avoid crops flooding, because this can cause root asphyxia and loss of productivity [13]. Then, they control several water pumps in the wetland (inside and outside of the protected area), and they turn them on after important rain event to discharge water through the irrigation channels to the sea. This evacuating capacity is not homogenous in all the wetland, Gandia has more facilities, while Xeraco and especially Xeresa have more difficulties due to the abandonment or disappearance of hydraulic infrastructures (i.e. Escorredor de Xeresa).

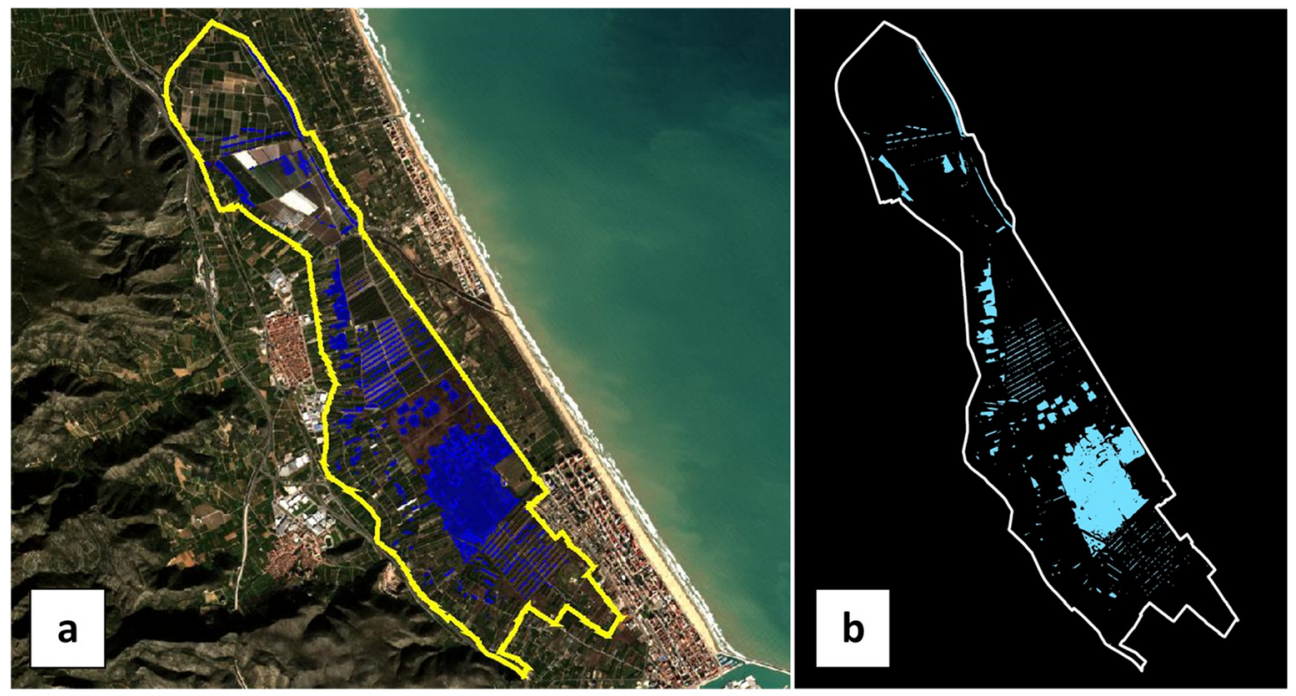

Figure 5: $\quad$ La Safor wetland: (a) Natural colour image and NDWI mask, January 16, 2017; and (b) NDWI mask with higher contrast, January 16, 2017. 

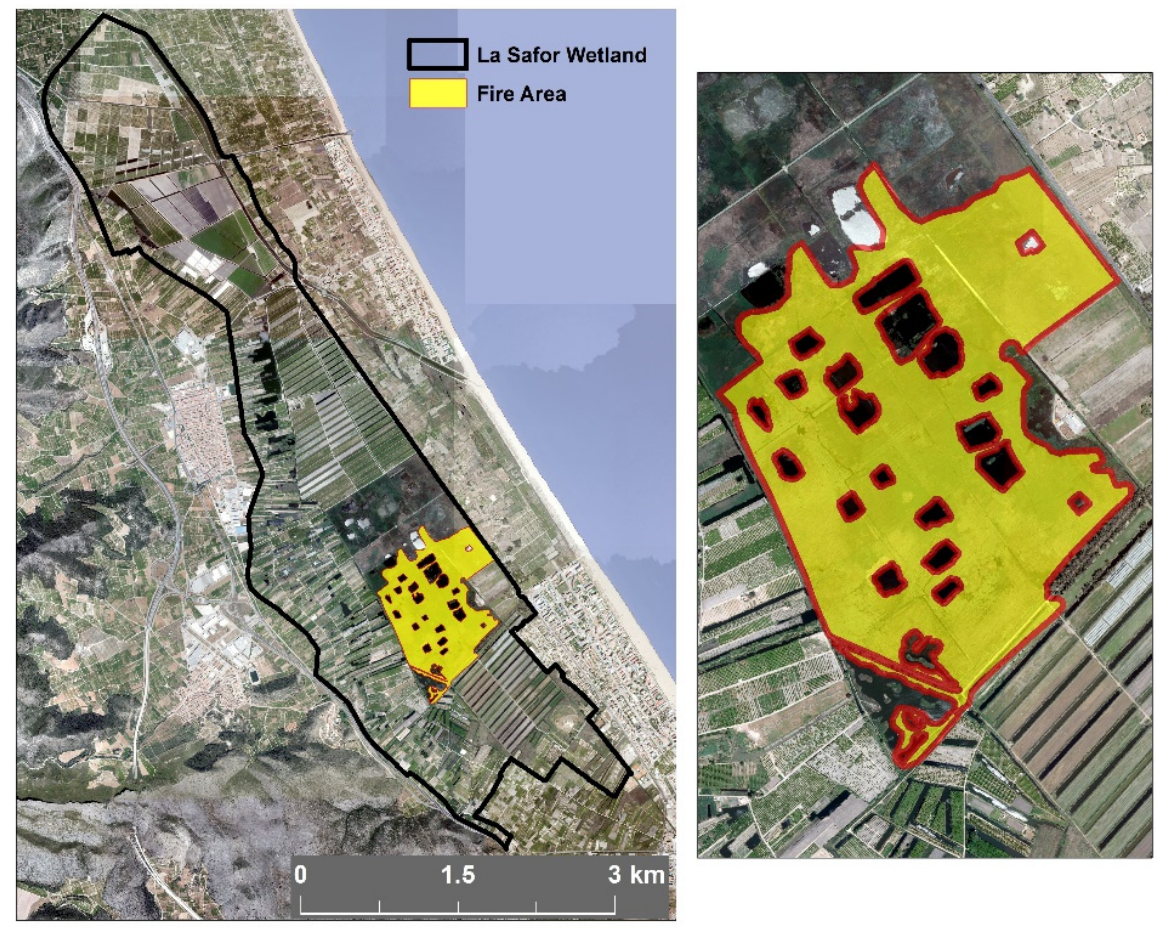

Figure 6: In yellow: fire area burned on November 9, 2016 the in La Safor wetland.

In $2014,91.9 \%$ of La Safor Wetland was private land, divided in small properties and big farms. There is consensus that private land ownership complicates management of protected areas and limits the scope of action of the various administrations [1]. One solution to this increasing problem is the purchase of land by the administration [14]. In 2018, the Territorial Action Plan for the Green Infrastructure of the Coast of the Valencian Community was passed by Decree 58/2018, dated May 4. Thanks to the approval of this plan, the public administration has been able to buy several plots on the north limit of the Gandia beach urban area. This action makes possible the recovery of the "Escorredor de Xeresa" old watercourse through this current public land.

The corrective measures that are included in small projects competing for different fund sources, such as European funds, are based on this analysis of land uses, the LIDAR-derived DEM and the map of flooded areas by NDWI index. Corrective measure must also have into account the need of considering all conflicting uses and ecosystem services provided by the wetland for integral management. The first measure is the restoration of the Channel Travessera (Fig. 1). Currently, this is the main discharge of the wetland area in the municipalities of Xeresa and Xeraco. The restoration will be executed in different phases. The main objective is elevating the separation between the marsh and the crop area and building discharge connections between them. So, in case of important rain event the agricultural area can drain to the marsh area, and to the ponds. This measure will fulfil different purposes, it will reduce the flooding problems of the agricultural area, it will increase the flooded area in the marsh, and it will allow a higher recharge of the aquifer avoiding direct discharge to the sea. 


\section{CONCLUSION}

The remote sensing and Airborne LiDAR data analysis allowed to identify and map the flooded surface. For successful wetland management, it is key having into account all conflicting uses and ecosystem services provided by the wetland. In wetlands coexist uses with different needs such as agricultural and environmental use, and managers need to reach an equilibrium. Agriculture is consolidated in the La Safor wetland after long time, and it has implemented some measure to avoid productivity loss that are not the best environmentally (i.e. water pumps draining the fields to the sea). After our analysis, the corrective measures proposed a search to increase the flooded marsh area and protect the fields, allowing a higher recharge of the aquifer.

\section{ACKNOWLEDGEMENTS}

The authors want to thank the Xeresa Council and Xeraco Council for sharing information.

\section{REFERENCES}

[1] Sebastiá-Frasquet, M.-T., Altur, V. \& Sanchis, J.-A., Wetland planning: Current problems and environmental management proposals at supra-municipal scale (Spanish Mediterranean coast). Water, 6, pp. 620-641, 2014.

[2] Convention on Wetlands of International Importance (Ramsar Convention). www.ramsar.org. Accessed on: 13 Jun. 2020.

[3] Millennium Ecosystem Assessment, Ecosystems and Human Well-Being: Synthesis, Island Press: Washington, DC, 2005.

[4] Mitsch, W.J., Bernal, B. \& Hernandez, M.E., Ecosystem services of wetlands. International Journal of Biodiversity Science, Ecosystem Services \& Management, 11(1), pp. 1-4, 2015.

[5] Why are Wetlands Important? U.S. Environmental Protection Agency, Wetlands Protection and Restoration. https:/www.epa.gov/wetlands/why-are-wetlandsimportant. Accessed on: 13 Jun. 2020.

[6] Balmford, A. et al., Economic reasons for conserving wild nature. Science, 297(5583), pp. 950-953, 2002.

[7] Pena-Regueiro, J., Sebastiá-Frasquet, M.-T., Estornell, J. \& Aguilar-Maldonado, J.A., Sentinel-2 application to the surface characterization of small water bodies in wetlands. Water, 12, pp. 1487, 2020.

[8] Huang, C., Peng, Y., Lang, M., Yeo, I.-Y. \& McCarty, G., Wetland inundation mapping and change monitoring using Landsat and airborne LiDAR data. Remote Sensing of Environment, 141, pp. 231-242, 2014.

[9] Zhou, Y. et al., Open surface water mapping algorithms: A comparison of waterrelated spectral indices and sensors. Water, 9, pp. 256, 2017.

[10] Tian, S., Zhang, X., Tian, J. \& Sun, Q., Random forest classification of wetland landcovers from multi-sensor data in the arid region of Xinjiang, China. Remote Sensing, 8, pp. 954, 2016.

[11] Hladik, C. \& Alber, M., Accuracy assessment and correction of a LIDAR-derived salt marsh digital elevation model. Remote Sensing of Environment, 121, pp. 224-235, 2012.

[12] AVAMET. Valencian Association of Meteorology. https://www.avamet.org/. Accessed on: 13 Jun. 2020. 
[13] Sebastiá, M.-T., Rodilla, M., Sanchis, J.-A., Altur, V., Gadea, I. \& Falco, S., Influence of nutrient inputs from a wetland dominated by agriculture on the phytoplankton community in a shallow harbour at the Spanish Mediterranean coast. Agriculture, Ecosystems \& Environment, 152, pp. 10-20, 2012.

[14] Maltby, E., Acreman, M., Blackwell, M.S.A., Everard, M. \& Morris, J., The challenges and implications of linking wetland science to policy in agricultural landscapesExperience from the UK National Ecosystem Assessment. Ecological Engineering, 56, pp. 121-133, 2013. 